\title{
Effect of Helicobacter pylori eradication on the natural history of duodenal ulcer disease
}

\author{
N Goggin, M Rowland, C Imrie, D Walsh, M Clyne, B Drumm
}

\begin{abstract}
Background-Duodenal ulcer disease is strongly associated with Helicobacter pylori infection of the gastric mucosa. Eradication of $\mathrm{H}$ pylori from the gastric mucosa in adults is associated with long term healing of ulcers.

Aims-To follow a cohort of children with duodenal ulcer disease for a minimum of two years after the eradication of $H$ pylori. Patients and methods-Over a three year period, all children diagnosed with duodenal ulcer disease had their symptoms documented and their $H$ pylori status evaluated. The histories of these children were carefully screened to determine previous symptoms and to document previous treatment regimens.

Results-Sixteen children were diagnosed with ulcers and 15 were available for treatment and long term follow up. The median age at which symptoms first occurred was 10.5 years (range, 6-14) and the median duration of symptoms was 24 months (range, 2-60). Ten of the children had been treated with $\mathrm{H}_{2}$ receptor antagonists for a median of 3.5 months (range, 1-60). Duodenal ulcers healed in all children after eradication of $\boldsymbol{H}$ pylori and all children have remained asymptomatic for a median of 37 months (range, 26-62). No child has required subsequent admission to hospital.

Conclusion-Eradication of $\mathrm{H}$ pylori is very effective in the long term healing of duodenal ulcer disease. $H$ pylori eradication should be the standard treatment for all infected children who present with duodenal ulcer disease.

(Arch Dis Child 1998;79:502-505)
\end{abstract}

Department of

Keywords: Helicobacter pylori; duodenal ulcer

Paediatrics, University

College Dublin and

The Children's

Research Centre, Our

Lady's Hospital for

Sick Children,

Crumlin, Dublin 12,

Ireland

N Goggin

M Rowland

C Imrie

D Walsh

M Clyne

B Drumm

Correspondence to:

Prof Drumm.

email: Paeds@

Crumlin.ucd.ie

Accepted 17 June 1998

Helicobacter pylori is a Gram negative, spiral shaped organism, which colonises the stomach and causes gastritis in both adults and children. ${ }^{1-4} H$ pylori gastritis is strongly associated with duodenal ulcer disease. Studies in adults indicate that eradication of $H$ pylori from the gastric mucosa is associated with long term healing of duodenal ulcers. ${ }^{56}$ As in adults, duodenal ulcer disease in children is a chronic relapsing condition. ${ }^{7}$ However, studies of duodenal ulcer disease in children are difficult to perform because of the low prevalence of the condition in this age group. The aim of our study was to follow a cohort of children with duodenal ulcers for two years after the eradication of $H$ pylori to determine the effect of this treatment on the natural history of duodenal ulcer disease.

\section{Methods}

PATIENTS

Over a three year period (1991-94), 376 children underwent upper gastrointestinal endoscopy. Table 1 outlines the major indications for endoscopy in these children. Sixteen children had a duodenal ulcer identified at endoscopy. All 16 had $H$ pylori colonisation of the gastric mucosa. Among the remaining 360 children, $63(17 \%)$ had $H$ pylori infection. All of the children had their symptoms assessed. These included the presence and duration of abdominal pain, nocturnal awakening, relief of pain by food, vomiting, melaena, and haematemesis. The presence of epigastric tenderness and a positive family history of peptic ulcer disease were also recorded.

To evaluate the chronicity of symptoms in the children who had duodenal ulceration, the number of months during which $\mathrm{H}_{2}$ receptor antagonists or other antacid medication had been prescribed before endoscopy was recorded. The past histories of these patients were reviewed to document previous hospital admissions, haemoglobin levels, and administration of blood transfusions.

ENDOSCOPY AND BIOPSIES

Endoscopy was carried out under general anaesthesia using a paediatric Olympus GIF XP10 or Q200 (Keymed, Dublin, Ireland) gastroscope after an overnight fast. During endoscopy, two biopsies were obtained from the first part of the duodenum. At least two biopsies were then taken from the antral mucosa, one of which was used for a rapid urease test (Clo Delta West, Bentley, Australia) and the second for histological assessment. In 12 of the 16 children, an additional antral biopsy specimen was obtained for culture.

Gastric and duodenal biopsies were fixed in

$10 \%$ neutral formalin, embedded in paraffin wax, and cut at $5 \mu \mathrm{m}$. The sections were stained with haematoxylin and eosin for light microscopy. Gastritis was defined according to

Table 1 Major indications for upper gastrointestinal endoscopy

\begin{tabular}{ll}
\hline Indication & $\begin{array}{l}\text { Number of } \\
\text { patients }\end{array}$ \\
\hline Chronic abdominal pain & 92 \\
Vomiting & 72 \\
Small bowel biopsy & 63 \\
Haematemesis & 17 \\
Oesophageal varices (sclerotherapy) & 14 \\
Irritability (?oesophagitis) & 31 \\
Crohn's disease & 87 \\
\hline
\end{tabular}


Table 2 Symptoms in 15 children with duodenal ulcers

\begin{tabular}{lll}
\hline Symptoms & Presentation & Follow up \\
\hline Abdominal pain & 15 & $4^{\star}$ \\
Nocturnal awakening & 13 & 0 \\
Pain relieved by food & 10 & 0 \\
Vomiting & 3 & 0 \\
Melaena & 6 & 0 \\
Haematemesis & 3 & 0
\end{tabular}

Follow up was at one month after completion of treatment *Abdominal pain cleared in all children at a mean of 3.7 months following eradication of Helicobacter pylori.

established histological criteria using the Sydney classification. ${ }^{9}$ Chronic, non-specific duodenitis was defined according to Hasan et al. ${ }^{10}$ Duodenitis was characterised by the presence of neutrophils in the lamina propria, crypts, or surface epithelium, in addition to an increase in the number of mononuclear cells. All biopsies were examined by a pathologist who was unaware of the clinical history, endoscopic findings, or the urease test results. Formalin fixed specimens were stained with cresyl violet to identify $H$ pylori. The organisms were identified easily because of their spiral or curved shape and their unique location beneath and within the mucous layer.

Gastric biopsy specimens were cultured on Columbia blood agar (Gibco, Paisley, UK) plates containing $7 \%$ defibrinated horse blood in an atmosphere of $5 \% \mathrm{O}_{2}$ and $10 \% \mathrm{CO}_{2} .{ }^{11}$ They were identified as $H$ pylori on the basis of colony morphology, Gram stain, and the production of urease, oxidase, and catalase.

The confirmation of $H$ pylori infection was based on the results of the rapid urease test, staining of biopsy sections, and culture. Children were considered infected if two of the three tests were positive. $H$ pylori was considered eradicated following treatment if culture, the rapid urease test, and cresyl violet staining of the gastric mucosa were all negative.

TREATMENT AND FOLLOW UP

Patients infected with $H$ pylori were treated with colloidal bismuth subcitrate $(480 \mathrm{mg} /$ $1.73 \mathrm{~m}^{2}$ body surface area per day divided into four doses), combined with a single antibiotic agent metronidazole, amoxycillin, or tetracycline for two weeks, depending on the treatment protocol in use at the time of diagnosis. All other medications including $\mathrm{H}_{2}$ receptor antagonists and antacids were discontinued at the time of endoscopy.

At least four weeks after completion of treatment, symptoms were reassessed and upper gastrointestinal endoscopy was repeated. $\mathrm{Pa}$ tients who remained infected with $H$ pylori after the first course of treatment were retreated with bismuth combined with a different antibiotic. They had a repeat endoscopy and reassessment of symptoms one month after the completion of the second course of treatment.

The children were seen at least once every six months as outpatients. They were reassessed in relation to symptoms, clinical findings, and use of $\mathrm{H}_{2}$ receptor antagonists or antacids at all follow up visits.
CONSENT AND ETHICS

Informed consent was obtained from the children's parents and the study was approved by the ethics committee at Our Lady's Hospital for Sick Children, Dublin.

\section{Results}

During a three year period, 16 children were found to have primary duodenal ulcers. One patient was lost to follow up and was excluded from further analysis. The children ranged in age from 9.8-14.25 years (median, 12.6) and the boy:girl ratio was $2: 1$. None of the children had a history of smoking, alcohol consumption, or ingestion of known ulcerogenic drugs. Nine of the 15 children had a first degree relative with peptic ulcer disease.

All 15 children had duodenal ulcers identified at endoscopy. All of the ulcers were located in the first part of the duodenum. Thirteen patients had nodularity of the antral mucosa creating a cobblestone appearance.

\section{SYMPTOMS}

Table 2 outlines presenting symptoms. All 15 children had abdominal pain which was associated with nocturnal awakening in 13 and relieved by food in 10. Gastrointestinal bleeding occurred in six children.

Fourteen children had a history of recurrent or chronic symptoms. The median age of onset of symptoms was 10.5 years (range, $6-14$ ). The median duration of symptoms was 24 months (range, 2-60). Six children had at least one previous admission to hospital because of symptoms. Six children had a haemoglobin level $<90 \mathrm{~g} / 1$ documented since the onset of symptoms and three had required a blood transfusion.

USE OF ANTACIDS AND $\mathrm{H}_{2}$ RECEPTOR ANTAGONISTS

Before inclusion in this study, 10 children had used $\mathrm{H}_{2}$ receptor antagonists. Nine of these children had received repeated courses of treatment because of relapsing symptoms. The median duration of use of $\mathrm{H}_{2}$ receptor antagonists was 3.5 months (range, 1-60). Five children were using antacids intermittently since the onset of their symptoms and four of these children were also using $\mathrm{H}_{2}$ receptor antagonists. Seven of the nine children requiring repeated courses of $\mathrm{H}_{2}$ receptor antagonists suffered relapses, with an exacerbation of symptoms when the medication was discontinued. The remaining two obtained no relief while using these medications.

DIAGNOSIS OF H PYLORI

$H$ pylori infection was present in all 15 children with duodenal ulcer disease. All had a positive rapid urease test (Clo Delta West). H pylori was identified using the cresyl violet stain in 14 of 15 children. Culture was positive in each of the 12 children in whom it was performed. Both culture and the rapid urease test were positive in the child who was negative on histology. 
Table 3 Long term follow up of children after eradication of Helicobacter pylori

\begin{tabular}{ll}
\hline Feature & \\
\hline Duration of follow up (months) & Median, 37 \\
& Range, 26-62 \\
Follow up longer than 24 months & 15 patients \\
Symptoms & 0 patients \\
Asymptomatic & 15 patients \\
Medication after $H$ pylori eradication & \\
$\mathrm{H}_{2}$ receptor antagonists & 0 patients \\
Antacids & 0 patients \\
Hospital admissions & 0 patients \\
\hline
\end{tabular}

All 15 children had histological evidence of chronic gastritis. Four patients had acute duodenitis and five had chronic duodenitis on histology.

TREATMENT AND FOLLOW UP

$H$ pylori infection was eradicated after the first course of treatment in 10 children who were treated with colloidal bismuth subcitrate and metronidazole. A subsequent course of treatment using colloidal bismuth subcitrate combined with either metronidazole $(n=2)$, amoxycillin $(\mathrm{n}=1)$, or tetracycline $(\mathrm{n}=2)$ eradicated $H$ pylori in the remaining five children. At endoscopy, the duodenal ulceration was healed in all patients after eradication of $H$ pylori. Eleven patients had residual antral nodularity noted despite clearance of $\mathrm{H}$ pylori.

All 15 children reported an improvement in symptoms (table 2). Eleven were asymptomatic. Four continued to have intermittent abdominal pain for a median of 8 weeks (range, 3-24 weeks) after eradication of $H$ pylori. This pain was less severe and less frequent than the original pain. Subsequently, these four children became asymptomatic. None of the 15 children had vomiting, nocturnal awakening, or gastrointestinal bleeding after treatment.

The children have been reviewed at least once every six months as outpatients. They have been followed for a median of 37 months (range, 26-62) (table 3). All 15 children have been followed for longer than 24 months and eight have been followed for three years or longer. All of the children remain asymptomatic. None have required treatment with $\mathrm{H}_{2}$ receptor antagonists or antacids since the eradication of $H$ pylori. No child has subsequently required admission to hospital.

\section{Discussion}

Our study is the first to report the long term follow up of children with duodenal ulceration after eradication of $H$ pylori. Israel and Hassal previously reported healing of duodenal ulcer disease in eight children cleared of $H$ pylori infection. ${ }^{12}$ However, they could not comment on long term healing of duodenal ulceration because some of these eight children were only followed for a period of three months and the mean period of follow up was only 6.5 months. In contrast, the median period of follow up in our study was over three years.

Our study demonstrates a remarkable change in the natural history of duodenal ulcer disease in children if $H$ pylori is eradicated from the gastric mucosa at the time of treatment.
These children are now asymptomatic over a prolonged period after treatment. This contrasts greatly with their history before the eradication of $\mathrm{H}$ pylori. Before this treatment most of the children had a history of chronic symptoms, which were relieved by acid suppression but relapsed when such treatment was discontinued. It is unclear why four of the children had some abdominal pain for a number of months after treatment. It is difficult to assess the significance of this pain because the more objective and severe symptoms of nocturnal awakening, vomiting, and upper intestinal bleeding had all cleared immediately after treatment. None of the children have had a relapse of abdominal pain or of their more severe symptoms over the follow up period. Furthermore, none of the children have required any further treatment with antacids or acid reducing agents.

Our findings are consistent with the findings in adult patients, where duodenal ulcers have been shown not to relapse if $H$ pylori is eradicated from the stomach. The natural history of duodenal ulcer disease in children is very similar to that reported in adults. ${ }^{78}$ In adults, treatment with $\mathrm{H}_{2}$ receptor antagonists or other acid reducing agents usually results in healing of duodenal ulcers. However, $60-80 \%$ of ulcers recur within six months of the discontinuation of these therapeutic agents. ${ }^{13}$ Studies of children have confirmed that although duodenal ulcers respond to treatment with $\mathrm{H}_{2}$ receptor antagonists, ulcer disease recurs rapidly after withdrawal of treatment. ${ }^{78}$

Because of the low prevalence of duodenal ulcer disease in children, ${ }^{14}{ }^{15}$ our study was carried out over a period of three years. The low prevalence of duodenal ulcer disease is confirmed because the paediatric gastroenterology service at our hospital is based on a population of 3.5 million people, with approximately 1 million children. Because of the long duration of the study, different treatment regimens were used to eradicate $H$ pylori. However, the purpose of this study was not to assess the efficacy of the treatment regimens but rather to document the natural history of duodenal ulcer disease after eradication of the infection. Recently, we have shown that a one week treatment regimen is very effective in eradicating $H$ pylori infection in children. ${ }^{16}$

It is not fully understood how an infection of the gastric mucosa has such a vital role in the pathogenesis of duodenal ulcers. This is especially true because $H$ pylori has been shown to have a remarkable tropism for gastric cells and will not colonise duodenal tissue. ${ }^{17}$ In a recent study, we showed that gastric metaplasia in the duodenum is a very significant risk factor for the development of duodenal ulcers in children with $H$ pylori infection. ${ }^{18}$ These areas of gastric metaplasia in the duodenum probably become infected with $H$ pylori.

The question of whether duodenal ulcer disease in children should be treated at the outset with anti- $H$ pylori agents needs to be addressed. A consensus statement issued by the National Institute of Health in the USA recommends that duodenal ulcer disease in 
adults should be treated in such a way. ${ }^{19}$ In view of the findings of our study, we feel that the same approach has to be adopted when treating children with $H$ pylori infection and duodenal ulceration. It is unfair to treat these children with acid suppressing agents, knowing that most of them will have a relapse of their disease within a short period of withdrawing the treatment, when we have shown that eradication of $H$ pylori will result in long term healing of duodenal ulcers.

This study was presented at the British Paediatric Association annual meeting, Warwick, 1995 and published in abstract form.

1 Drumm B, Sherman P, Cutz E, Karmali M. Association of Campylobacter pylori on the gastric mucosa with antral gastritis in children. N Engl F Med 1987;316:1557-61.

2 Drumm B, Perez-Perez GI, Blaser MJ, Sherman PM. Intrafamilial clustering of Helicobacter pylori infection. $N$ Eng f Med 1990;322:359-63.

3 Warren JR, Marshall BJ. Unidentified curved bacilli on the gastric epithelium in active chronic gastritis. Lancet 1983;i 1273-5.

4 Peterson WL. Helicobacter pylori and peptic ulcer disease. N Engl f Med 1991;324:1043-8.

5 Coughlan JG, Gilligan D, Humphries $\mathrm{H}$, et al. Campylobacter pylori and recurrence of duodenal ulcers-a 12 month follow up study. Lancet 1987;ii:1109-11.

6 Hentschel E, Brandstatter G, Dragosics B, et al. Effect of ranitidine and amoxycillin plus metronidazole on the eradication of Helicobacter pylori and the recurrence of duodenal ulcer. N Engl f Med 1993;328:308-12.
7 Murphy MS, Eastham EJ, Jimenez M, Nelson R, Jackson RH. Duodenal ulceration: review of 110 cases. Arch Dis RH. Duodenal ulceration
Child 1987;62:544-58.

8 Drumm B, Rhoads JM, Stringer DA, et al. Peptic ulcer disease in children: etiology, clinical findings and clinical course. Pediatrics 1988;82:410-14.

9 Price AB. The Sydney system: histological division. $\mathcal{f}$ Gastroenterol Hepatol 1991;6:209-22.

10 Hasan M, Sircus W, Ferguson A. Duodenal mucosal architecture in non specific and ulcer associated duodenitis. Gut 1983;22:637.

11 Clyne M, Drumm B. Adherence of Helicobacter pylori to primary human gastrointestinal cells. Infect Immun 1993; 61:4051-7.

12 Israel D, Hassall E. Treatment and long term follow-up of Helicobacter pylori-associated duodenal ulcer disease in children. F Pediatr 1993;123:53-8

13 Graham DY, Lew GM, Klein PD, et al. Effect of treatment on the long term recurrence of gastric or duodenal ulcer. A randomized, controlled study. Ann Intern Med 1992;116: 705-8.

14 Drumm B, Gormally S, Sherman PM. Gastritis and peptic ulcer disease. In: Walker WA, Durie PR, Hamilton GR, Walker-Smith JA, Watkins JB, eds. Pediatric gastrointestinal disease, 2nd ed. St Louis: Mosby, 1995:506-28.

15 Gormally SM, Prakash N, Durnin MT, et al. Symptoms in children before and after treatment of Helicobacter pylori children before and after treatment
infection. F Pediatr 1995;126:753-6.

16 Walsh D, Goggin N, Rowland M, Durnin M, Moriarty S, Drumm B. One week treatment for Helicobacter pylori infection. Arch Dis Child 1997;76:352-5.

17 Clyne M, Labigne A, Drumm B. Helicobacter pylori requires an acidic environment to survive in the presence of urea. Infect Immun 1995;63:1669-73.

18 Gormally SM, Kierse BM, Daly LE, et al. Gastric metaplasia and duodenal ulcer disease in children. Gut 1996;38: 513-17.

19 National Institute of Health. Helicobacter pylori in peptic ulcer disease. NIH Consensus Statement 1994;12:1-23. 